Revista de

Contabilidade e

Organizações

www.rco.usp.br
DOI: http://dx.doi.org/10.11606/issn.1982-6486.rco.2020.163964

Journal of

Accounting and

Organizations

\title{
Gestão de riscos no setor público brasileiro: uma nova lógica de accountability?
}

\author{
Risk management in the Brazilian public sector: a new logic of accountability?
}

Vitor Hugo Klein Junior ${ }^{\mathrm{a}}$

${ }^{a}$ Departamento de Governança Pública da Universidade do Estado de Santa Catarina

Palavras-chave

\section{Gestão de riscos.}

Accountability.

Controle interno.

Auditoria interna.

Setor público.
Keywords

Risk management.

Accountability.

Internal controls.

Internal audit.

Public sector.

\section{Resumo}

Diferentes governos têm adotado a gestão de riscos como parte de um novo padrão de excelência para o controle interno. O modelo de regulação baseado no risco, no entanto, requer a rearticulação do controle em torno de uma nova lógica de accountability, por meio da qual órgãos de controle devem redefinir os limites da ação e responsabilidade pública. As consequências dessa agenda no contexto brasileiro, entretanto, carecem de estudos. Este artigo examina os desafios de implementação da gestão de riscos em um governo estadual, em termos do impacto dessa inovação nas formas de prestação de contas e enforcement de agentes públicos. Com base em 13 rodadas de entrevistas e observação participante, os resultados demonstram que, apesar da gestão de riscos servir para legitimar a expansão do controle interno, a assimilação dessa inovação encontra barreiras na identidade profissional de auditores, na baixa relevância de controles internos e na dificuldade de disclosure de riscos estratégicos. $\mathrm{O}$ artigo contribui ao propor que, desacoplada de uma reformulação dos incentivos para a transparência de problemas estruturais, a gestão de riscos tem alcance limitado no enfrentamento de riscos sistêmicos no setor público.

\begin{abstract}
Different governments have adopted risk management as part of a new standard of excellence for internal controls. Risk-based regulation, however, implies on the articulation of a new logic of accountability, one where control bodies have to redefine the limits of public action and responsibility. The consequences of this agenda in the Brazilian context, however, remain underexplored. This paper examines the challenges of implementing risk management in a state government, in terms of its impact on the forms of answerability and enforcement of public agents. Based on 13 rounds of interviews and participant observation, findings show that, while risk management served to legitimate the expansion of internal controls, the assimilation of this innovation faces limitations regarding the professional identity of auditors, the low relevance of internal controls, and conflicts of disclosure of strategic risks. The paper contributes by proposing that risk management has limited capacity to address systemic risks in the public sector, when decoupled from a reformulation of incentives for making structural problems transparent.
\end{abstract}

\section{Implicações práticas}

A discussão interessa aos órgãos e agentes de controle envolvidos com a modernização do controle no setor público. Os resultados demonstram que desacoplada de uma reformulação dos incentivos para a transparência e divulgação de problemas estruturais, a gestão de riscos tem alcance limitado no enfrentamento de riscos sistêmicos.

Copyright (C) 2020 FEA-RP/USP. Todos os direitos reservados 


\section{INTRODUÇÃO}

Diferentes governos têm adotado a gestão de riscos como parte de um novo padrão de excelência para o controle interno (IFAC, 2014; IIARF, 2009; OCDE, 2010). Ao integrar controle e gestão, a gestão de riscos surge como um conjunto de práticas, instrumentos e papéis, cuja promessa é melhorar a decisão governamental e o desempenho dos serviços públicos (Souza, Braga, Cunha, \& Sales, 2020; Vieira \& Barreto, 2019). Estudos empíricos, no entanto, tem notado que a assimilação dessa agenda é permeada por conflitos, tensões e dinâmicas complexas (Beassuier, Demeritt, Griffiths, \& Rothstein, 2016; Carlsson-Wall, Kraus, Meidell, \& Tran, 2017; Oulasvirta \& Anttiroiko, 2017; Rana, Wickramasinghe, \& Bracci, 2019). Mais do que um meio de buscar eficiência, portanto, a gestão de riscos introduz uma nova lógica de accountability no setor público, cujas consequências devem ser compreendidas (Power, 2004; Rothstein, Huber, \& Gaskell, 2006).

Gerir riscos significa que agentes públicos devem não apenas antecipar informações a respeito de ameaças a objetivos organizacionais, mas também tornar essas informações passíveis de auditoria e responsabilização. Para Black (2005), isso implica em uma mudança radical, uma vez que órgãos de controle devem ser capazes de definir os limites da ação e responsabilização de agentes públicos, isto é, definir como devem informar e justificar ações com base no risco (answerability) e como devem ser cobrados por essas ações (enforcement). A gestão de riscos, portanto, vira as organizações públicas de dentro para fora (Power, 2004), ao pressioná-las a externalizarem e justificarem as formas de controle que colocam em prática para mitigar ameaças a objetivos estratégicos. Tais mudanças, entretanto, passam por resistências, uma vez que agentes públicos evitam dar visibilidade a problemas que ameacem seu capital político (Hood, 2007; Weaver, 1986).

Embora a literatura tenha mapeado algumas das consequências da adoção da gestão de riscos no contexto internacional, ainda se sabe pouco sobre os efeitos dessa assimilação em contextos de reformas gerenciais inacabadas (Pinho, 2016; Souza, et al., 2020). Pesquisas têm demonstrado que, nesses contextos, persistem as dificuldades na institucionalização de inovações de controle (Lino, Carvalho, Aquino, \& Azevedo, 2019). Este artigo contribui para essa literatura, ao examinar os desafios de implementação da gestão de riscos em um governo estadual, em termos do impacto dessa inovação nas formas de prestação de contas e enforcement de agentes públicos. O estudo foi realizado com base em 13 rodadas de entrevistas e observação participante com 21 agentes de controle (auditores e controladores internos) envolvidos na implementação de práticas de gestão de riscos em duas autarquias estaduais.

Teoricamente, o estudo se baseou em abordagens que focam no trabalho de atores situados na implementação de práticas de gestão de riscos (Carlsson-Wall, et al., 2017; Jordan, Mitterhofer, \& Jørgensen, 2018; Jørgensen \& Jordan, 2016; Maguire \& Hardy, 2016). Partindo da premissa de que o sucesso e as limitações da gestão de riscos passam pela investigação da microdinâmica das relações entre atores, práticas, normas e papéis, tais estudos sublinham que conflitos e tensões são inerentes ao esforço em tornar a gestão de riscos operacional. Por meio de uma abordagem bottom-up, portanto, esses estudos oferecem descrições ricas dos bastidores (backoffice) do desenho e da implementação de práticas de gestão de riscos. Aplicado aqui, este corpo teórico auxiliou na compreensão da relação entre os esforços de implementação da gestão de riscos em um governo estadual e o surgimento (ou não) de diferentes formas de accountability (Power, 2016b).

Os resultados apontam que, embora a gestão de riscos tenha servido como um subsídio para os agentes de controle legitimarem a expansão do controle interno, isso não se traduziu em alterações nas formas de prestação de contas e responsabilização de agentes públicos. Desafios identificados - a lógica de atuação de auditores, a baixa relevância de controles internos e dificuldades de disclosure de riscos estratégicos - colocam barreiras para que essa inovação seja assimilada por gestores públicos.

O artigo contribui ao propor que, desacoplada de uma reformulação dos incentivos para a transparência de problemas estruturais no setor público, a gestão de riscos fica reduzida a uma ferramenta de melhoria de processos com alcance limitado para o enfrentamento de riscos sistêmicos. 


\section{GESTÃO DE RISCOS E UMA NOVA LÓGICA DE ACCOUNTABILITY}

A proliferação de práticas de gestão de riscos a partir da década de 1990 é um desdobramento da agenda da nova gestão pública (Carlsson-Wall, et al., 2017). No contexto anglo-saxão, essa proliferação fez parte de um processo de mudança que visava transformar culturas burocráticas, avessas ao risco, em culturas de inovação e cooperação interorganizacional (NAO, 2000). A identificação do Estado como gestor de riscos, no entanto, implicou em desafios em termos de prestação de contas e responsabilização de agentes púbicos.

Perspectivas voltadas à compreensão do trabalho de agentes envolvidos na concepção e implementação de práticas de gestão de riscos têm apontado que os ideais de integração da agenda de gestão de riscos são difíceis de colocar em prática, seja pelos papéis conflitantes dos diferentes atores envolvidos, seja pela maneira divergente como esses interpretam e utilizam as ferramentas de gestão de riscos (Arena, Arnaboldi, \& Palermo, 2017; Hall \& Fernando, 2016; Jørgensen \& Jordan, 2016). Assim, o processo de adaptação em diferentes culturas organizacionais pode resultar em aplicações e resultados diferentes dos promovidos por frameworks genéricos (Carlsson-Wall, et al., 2017; Oulasvirta \& Anttiroiko, 2017). Pesquisadores interessados na (micro) dinâmica organizacional envolvida na implementação da gestão de riscos, buscam entender como essas práticas influenciam e/ou modificam os regimes de accountability nos quais são introduzidas (Power, 2016b).

De acordo com Black (2005) a gestão de riscos implica em articular uma nova lógica de accountability no setor público. Segundo a autora, gerir riscos demanda que órgãos de controle sejam capazes de redefinir os parâmetros da culpabilidade e os limites da responsabilidade de agentes públicos, que, avessos a promoverem a divulgação de problemas (Hood, 2007), passam a atuar dentro de um regime de visibilidade e escrutínio público. Mais do que gerenciar ameaças à alguma política ou objetivo, portanto, gestores públicos passam a ser mais sensíveis a reputação pessoal ou institucional. Tal mudança é um desafio para controladores internos, os quais passam a trabalhar muito além da lógica de conformidade financeira e contábil, tendo que se envolver na persuasão de gestores à adoção de práticas de gestão de riscos (Hall, Mikes, \& Millo, 2015).

Power (2004, 2009), por exemplo, tem alertado sobre as implicações do empoderamento de controladores internos. Por um lado, esse empoderamento faz com que controladores internos passem a assumir protagonismo em áreas como estratégia e comunicação organizacional; por outro lado, esses atores são forçados a trabalhar no limiar do gerenciável, dada a natureza elusiva do risco. O risco, nesse caso, é que a aplicação cerimonial de práticas de gestão de riscos leve a uma espécie de "miopia induzida pelo processo" (Black, 2005, p. 541). Ou seja, em vez de salvaguardar a administração pública de ameaças sistêmicas, a gestão de riscos funcionaria como um meio de deslocar a responsabilização de agentes para os processos (Hood \& Rothstein, 2000; Power, 2009) - "siga o framework e ninguém irá criticá-lo" (Black, 2005, p. 541).

Enquanto os desafios acima são descritos em ambientes de accountability relativamente desenvolvida (Rana, et al., 2019; Souza, et al., 2020), há uma carência de estudos sobre as consequências da adoção de práticas de gestão de riscos em contextos de reformas gerenciais parciais ou inacabadas. A próxima seção revisa algumas das barreiras para essa assimilação no contexto brasileiro.

\section{CONTROLE INTERNO E ACCOUNTABILITIY NO SETOR PÚBLICO BRASILEIRO}

Para compreendermos os desafios que a adoção da gestão de riscos impõe para o controle da administração pública brasileira, é importante olharmos para o contexto histórico e institucional do controle interno. A constituição federal de 1988 é considerada o marco normativo do sistema de controle interno da administração pública (Machado \& Paschoal, 2016). A institucionalização desse sistema foi marcada por resistências que determinaram as formas de prestação de contas e responsabilização que acabaram prevalecendo (Sacramento \& Pinho, 2016). Como relata Castro (2015), a atuação do controle pós-1988 acabou consignada à uma perspectiva de auditoria; e os esforços para o desenvolvimento de um viés gerencial para o controle esbarraram na lógica de correição que prevaleceu. Escândalos da época (CPI Governo Collor; CPI do Orçamento) acabaram reforçando o enfoque formal-legalista de atuação do controle, ao induzirem a institucionalização de formas de responsabilização que preveem, por exemplo, a punição para dirigentes públicos, mecanismos de avaliação e julgamento dos atos de gestão, e regras para compras e contratações no serviço público.

Nos anos 2000, a CGU protagonizou iniciativas para ampliar o escopo do controle interno, pressionando municípios a incorporarem iniciativas para transparência (Loureiro, Abrucio, \& Teixeira, 2012). No entanto, esses esforços não se traduziram em um reposicionamento do controle com foco na gestão, uma vez que a lógica de conformidade ainda domina a agenda de controladores (Aquino, Rocha, Olivieri, \& Pinho, 2018; Ungaro \& Soré, 2014). 
Lino et al. (2019), por exemplo, demonstram que esse reposicionamento não é apenas dependente de pressões externas, mas do trabalho institucional de atores com poder e influência. Outra razão para a persistência da lógica de controle baseada na conformidade, segundo Aquino et al. (2018, p. 124), é o distanciamento de agentes do controle em relação a seus jurisdicionados, ou seja, um baixo interesse na realização de auditorias presenciais, as quais permitiriam identificar riscos.

A ‘modernização' do controle interno esbarra, especialmente, nas dificuldades de institucionalização de práticas de accountability, as quais permitiriam superar o enfoque de controle formal legalista que prevaleceu (Pinho, 2016; Raupp \& Pinho, 2015). No caso das formas de prestação de contas, Sacramento e Pinho (2016) notam que, constitucionalmente, a dimensão da answerability acabou consignada aos aspectos financeiros e orçamentários do controle. Segundo os autores, essa redução do sentido da answerability desconsidera que a prestação de contas implica na produção de informações substantivas, as quais devem permitir a participação ativa dos cidadãos na avaliação do desempenho das políticas públicas. Com o foco das formas de responsabilização recaindo nos agentes públicos em vez da gestão, o sentido restrito de answerability impõe barreiras adicionais para que gestores públicos divulguem informações sobre riscos.

As barreiras apontadas se refletem no debate entre setores da gestão e do controle acerca da viabilidade de se produzir formas mais reflexivas de controle, necessidade evidenciada pelas controvérsias suscitadas pela PL 7448, a qual buscava modificar a Lei de Introdução às Normas do Direito Brasileiro. A intenção originária da PL era, segundo seus idealizadores, garantir segurança jurídica para a atuação de gestores públicos, pois eles estariam paralisados pela insegurança jurídica resultante do excesso de controles. A proposta foi amplamente criticada pelos órgãos do controle, que alegavam que o projeto limitaria a forma independente de atuação do controle. A controvérsia, contudo, demonstra precisamente a dificuldade em se rearticular formas de prestação de contas e enforcement, por meio das quais agentes públicos devem dar transparência a potenciais ameaças à alguma política pública.

\section{METODOLOGIA}

Durante 2017 e 2018, auditores internos de um governo estadual trabalharam para implementar a gestão de riscos como parte do rol de práticas de controle interno da administração pública do estado. A motivação desse grupo tinha raízes em fóruns de discussão, como o Conselho Nacional de Controle Interno-CONACI, e na observação de experiências de outras controladorias estaduais. Ao longo de dois anos, esse grupo participou de treinamentos, promoveu seminários e iniciou dois projetos para avaliar os desafios dessa implementação. O pesquisador acompanhou esses atores, com o objetivo de compreender como a adoção da gestão de riscos impactaria nas formas de engajamento dos órgãos a prestarem contas e a justificarem seus atos em nome do risco (answerability).

A pesquisa seguiu uma estratégia qualitativa, com utilização de entrevistas em profundidade e observação participante. Estudos sobre gestão de riscos de inspiração sociológica têm problematizado a necessidade de se compreender o trabalho (riskwork) de atores situados envolvidos na concepção e implementação de práticas de gestão de riscos (Carlsson-Wall, et al., 2017; Jordan, et al., 2018; Jørgensen \& Jordan, 2016; Maguire \& Hardy, 2016). Como relata Power (2016a), tais estudos compartilham o entendimento de que é preciso avançar investigações para além das análises post hoc das falhas de gestão de riscos, uma vez que as raízes de tais falhas são construídas em situações de normalidade (Bieder \& Bourrier, 2013; Vaughan, 1996). Esses estudos têm, dessa forma, produzido descrições detalhadas do trabalho de bastidores da gestão de riscos. Dois pressupostos comuns a essa literatura embasaram a pesquisa relatada aqui.

Primeiro, estudos demonstram existir um gap entre frameworks de gestão de riscos e como esses são articulados na prática, o que leva atores situados a questionamentos e inovações quando envolvidos na implementação (Carlsson-Wall, et al., 2017; Hall \& Fernando, 2016). Com base nesse pressuposto procurou-se entender como os atores investigados recepcionaram e mobilizaram as práticas de gestão de riscos de acordo com aquela realidade contextual. Segundo, uma vez que a implementação da gestão de riscos é permeada por resistências e conflitos de papéis (Hall, et al., 2015), procurou-se entender como especialistas no processo (auditores e controladores internos) lidaram com essas resistências e conflitos.

Com base nesses pressupostos, foram realizadas 13 rodadas de entrevistas em profundidade com auditores e controladores internos do estado (Quadro 1). A entrevista em profundidade buscou, por meio de um processo dialógico e conversacional (Godoi \& Mattos, 2006), possibilitar aprofundamento do pesquisador da realidade dos atores. No caso estudado, um roteiro foi elaborado para direcionar (probe) os entrevistados, mas sem impedi-los de falar livremente sobre aspectos que considerassem relevantes. 
Os atores foram entrevistados múltiplas vezes e roteiros diferentes foram elaborados para cada rodada. Por fim, a técnica de snowball foi utilizada para seguir outros atores relevantes; e o pesquisador participou de reuniões nas quais agentes de controle (auditores e controladores internos) discutiram resultados de implementação de práticas de gestão de riscos.

\begin{tabular}{ccclc}
\hline Nr. & Organ. & Data & \multicolumn{1}{c}{ Entrevistados } & Duração \\
\hline 1 & AIE & 04.05 .2017 & 1 Gerente de Auditoria de Pessoal e 8 auditores da folha & $* 30$ min \\
2 & AIE & 04.05 .2017 & 1 Gerente de Auditoria de Pessoal e 8 Auditores (8) & $02: 53: 51$ \\
3 & AIE & 26.05 .2017 & 1 Gerente de Controle Interno e 3 Auditores & $01: 08: 11$ \\
4 & AIE & 23.06 .2017 & 1 Gerente de Auditoria de Pessoal 2 Servidores de órgão e 3 auditores & $* 2: 30 \mathrm{~h}$ \\
5 & AIE & 15.09 .2017 & 2 Gerentes de auditoria, 1 Auditora, & $02: 00: 11$ \\
6 & MP & 26.03 .2018 & 1 Auditor Federal & $00: 14: 21$ \\
7 & AIE & 29.03 .2018 & 1 Gerente e 4 Auditores & $01: 53: 54$ \\
8 & TCE & 04.05 .2018 & 1 Diretor & $01: 59: 41$ \\
9 & CI 1 & 04.05 .2018 & 1 Controlador Interno & $00: 35: 57$ \\
10 & CI 2 & 08.06 .2018 & 1 Controlador Interno, 2 auditores, servidores e presidente da autarquia & $* 2 \mathrm{~h}$ \\
11 & CI 2 & 06.09 .2018 & 1 Controlador Interno & $01: 29: 94$ \\
12 & AIE & 28.03 .2019 & 1 Gerente e 3 Auditores & $01: 04: 20$ \\
13 & CI 2 & 28.03 .2019 & 1 Controlador Interno e 1 Gerente de Planejamento & $00: 52: 59$ \\
\hline
\end{tabular}

Quadro 1. Cronograma de entrevistas

Fonte: elaborado pelo autor.

Legenda: AIE (auditoria interna do estado; CI (controle interno de órgão); TCE (tribunal de contas do estado); MP (ministério do planejamento).

* participação em reuniões e discussões (não gravadas).

A análise dos dados seguiu uma abordagem abdutiva. Lukka e Modell (2010) explicam que, embora a abordagem abdutiva tenha similaridades à abordagem indutiva, uma vez que ambas partem de material empírico para gerar insight teórico, a abdução recorre a tudo o que é conhecido empiricamente e teoricamente sobre o fenômeno investigado. Assim, enquanto a indução é caracterizada por um processo semiautomático de generalização, a abdução envolve o desenvolvimento (a invenção) de explicações informadas teoricamente a respeito de situações novas ou inesperadas identificadas no material empírico.

Neste artigo, a abdução foi operacionalizada por meio da iteração entre dados coletados, conceitos teóricos existentes e categorias teóricas emergentes (Lukka \& Modell, 2010; Mantere \& Ketokivi, 2013). Duas etapas foram realizadas: a análise de primeira-ordem, na qual buscou-se compreender a perspectiva dos atores investigados (êmica); e a interpretação de segunda-ordem, por meio da qual procurou-se avançar o entendimento teórico do material (ética). Mais especificamente, essas etapas ocorreram da seguinte forma. Para cada entrevista foi elaborado um $\log$, no qual assuntos relacionados à pergunta de pesquisa foram destacados de acordo com categorias como "dificuldade de adoção", "impactos no papel da auditoria", "capacidade de controles internos", "sobrecarga de trabalho"; "sobreposição de competências" etc. Após a exaustão da coleta de dados, as entrevistas foram transcritas e relidas à luz dos logs e em relação aos pressupostos teóricos de pesquisa. Três temas emergiram: 1) Legitimação da expansão do sistema de controle interno; 2) Baixa relevância e capacidade limitada dos controladores internos; 3) Conflitos no disclosure de riscos estratégicos.

Explicados a seguir, esses resultados demonstram que a implementação da gestão de riscos não trouxe mudanças nas formas de prestação de contas e responsabilização de agentes públicos. Capitaneada por um grupo de auditores entusiastas, a gestão de riscos serviu como subsídio para que esse grupo questionasse e trabalhasse a forma de atuação de auditores e controladores internos. Esse processo, contudo, encontrou resistências, tanto entre auditores menos entusiastas, como entre os controles internos e gestores de autarquias. 


\section{RESULTADOS}

\section{Legitimação da expansão do sistema de controle interno}

Embora a implementação da gestão de riscos tenha sido parte de um projeto para legitimar a expansão da atuação da auditoria e controle interno (Black, 2005; Power, 2004), esse processo não contou com reformulações nas formas de prestação de contas e responsabilização de agentes públicos. Auditores entusiastas enxergavam a gestão de riscos como um meio de aperfeiçoar o sistema de controle interno do estado, perspectiva que, contudo, não era compartilhada pela maioria dos auditores (entrevistas 1 e 2). Assim, a adoção da gestão de riscos como rol de práticas de controle interno teve que passar pelo convencimento de atores relevantes (Hall \& Fernando, 2016; Hall, et al., 2015).

Em discussões, auditores problematizaram a relevância e as dificuldades de adotar a gestão de riscos como prática de controle interno e tentaram delimitar as fronteiras dessa prática (Mikes, 2011). Após um período de assimilação, concluíram que a implementação seria feita pela divisão de custeio, mas isto implicaria em rever formas de atuação.

(interlocutor 1) Já no ano passado e esse ano revimos a nossa forma de atuar [...] o que acontece no órgão e às vezes ele está cuidando das questões mais básicas, que nem sempre a possibilidade ou o impacto é muito considerável, e deixa de ver aquilo que realmente é importante, financeiramente ou institucionalmente ligado a possibilidade de uma fraude, ou risco e dano, ou prejuízo em mídia, é muito maior né, o certo seria isso, talvez a gente tivesse que ir lá ajudá-los no primeiro momento, a identificar onde é que estão esses possíveis pontos sensíveis, pontos de risco, será que não deveríamos fazer isso? (Auditoria Interna, Entrevista 3).

Dúvidas existiam sobre como a implementação nos órgãos (induzida pela auditoria) feria a lógica de atuação dos auditores. A ideia de que a gestão de riscos demandava um esforço de persuasão dos gestores (Hall, et al., 2015) conflitava com a identidade profissional dos auditores, os quais questionavam a relevância da forma existente de atuação, mas encontravam dificuldades em justificar uma lógica que conflitava com a ideia de independência e distância dos auditores.

(interlocutor 1) Isso era um grande obstáculo, até onde a auditoria pode avançar, qual é o papel da auditoria, qual o papel do dono do negócio, qual o papel do controle interno, dos controles internos, aí então a parte desse curso que ele disse "olha se não tiver mapeamento do processo, façam vocês", [...], porque era uma barreira, a gente não pode entrar na competência do outro, ou por motivo de legalidade, ou motivo de orgulho mesmo né...eu até brinco né, na realidade o auditor é sortudo né, que na verdade eles ficam ali na terceira linha de defesa, só monitorando o que os caras estão fazendo... (Auditoria Interna, Entrevista 5).

(interlocutor 1) ... aí como é que eu vou lá, tenho que empurrar goela abaixo, alguma coisa que o próprio gestor e o próprio órgão tem que fazer, como é que eu vou fazer isso, aí eu falei: "a gente faz isso, constrói junto com o controle interno, forçando um pouquinho a barra, para que possa começar a acontecer, ou a gente fica fazendo a nossa auditoria de conformidade e esquece o tema.

(interlocutor 2) Até porque a gente está vendo que... o nosso modus operandi ele não está tendo assim, um... a gente trabalha muito e... (Auditoria Interna, Entrevista 5).

Gradualmente os auditores entusiastas se convenceram de que a auditoria deveria atuar ex ante, como consultora de soluções e problemas nos órgãos. No entanto, ao longo dos dois anos, essa posição teve que ser promovida e defendida dentro da controladoria (Lino, et al., 2019). Uma das maneiras de "vender" a ideia, foi a realização de projetos pilotos, nos quais a escolha de dirigentes e controladores internos capazes de implementálos foi crucial.

\section{Baixa relevância e capacidade limitada dos controles internos}

A cautela na escolha de quais órgãos aplicar os pilotos, atrelava-se às carências identificadas em termos da capacidade operacional dos controles internos e do poder limitado desses em influenciar gestores na adoção de inovações. Segundo os auditores, para que a implementação fosse bem sucedida, os benefícios deveriam superar os custos problematizados em termos de materialidades que justificassem as mudanças. Isso os levou à uma adoção seletiva (Oulasvirta \& Anttiroiko, 2017), pois entendiam haver riscos na difusão da inovação. Na maioria dos órgãos, o controle interno cabia à uma pessoa, a qual carecia de competências básicas e acumulava conflitos de interesses que evidenciavam o baixo interesse da gestão nos controles internos. 
(interlocutor 2) - ...eles desconhecem o que eles têm que fazer nas questões de controle interno, então assim, só com a norma não adianta [...] a própria designação já é feita assim, meio quem está sobrando, ou é amigo do presidente, indicação de cargo...e tem aquele perfil que está ali para cumprir obrigação, esses fazem de conta que trabalham, e tem aqueles que são sinceros que falam "não, eu não fiz nada", eu tive que ficar estudando, ou fazer atribuições na gerência. Têm gerências onde o controlador responsável saiu de uma outra função, muitas vezes uma função de assessoria, de secretário, ou de gerente, então ele exerce várias funções ao mesmo tempo, e além de desempenhar suas funções ele participa das questões financeiras, parte do pessoal... (Auditoria Interna, Entrevista 3).

A implementação esbarrava, ainda, no desconhecimento dos dirigentes do papel dos controles internos.

(interlocutor 1)... na maioria dos casos, o despreparo dos gestores para entender que aquele setor de controle interno, é uma salvaguarda para ele, aquilo é uma blindagem para ele, aquilo é quem...é que vai dar um aviso para ele, um alerta para ele e alguma coisa está sendo feita de forma equivocada, e inevitavelmente vai sobrar para ele e no futuro [...] ele não tem essa percepção, e aí eles tratam isso com a menor importância... (Auditoria Interna, Entrevista 3)

Ainda, segundo auditores, sobrecarregados com as demandas do TCE (Tribunal de Contas do Estado), os secretários de controle interno deixavam para segundo plano o monitoramento e implementação de controles de gestão.

(interlocutor 1) -Tem a questão dos pareceres que eles são obrigados a fazer [TCE] a admissão, a prestação de contas, o caso da PM, do bombeiro, nas aposentadorias também [...] só que eles só conseguem fazer o parecer e não conseguem olhar outras áreas[...].

(interlocutor 2) - Conhecido como terceirização, o tribunal de contas terceiriza esse papel, mas aí ele não percebe [...] que na verdade ele inviabiliza...Por isso que às vezes, assim ó, nós estamos entrando ali na banca do tribunal de contas, eles podem determinar a nós [...] determinar que nós façamos auditoria no órgão x para tratar do tema y, então a gente fala assim "agora temos dois chefes", temos chefes do executivo, que tem essa prerrogativa, e tem o tribunal de contas... (Auditoria Interna, Entrevista 3).

As dificuldades sinalizadas não impediram que os auditores avançassem na implementação. $\mathrm{O}$ grupo entendia que a demanda viria de "cima para baixo", pois o governo federal já exigia que a administração direta e indireta adotasse práticas de gestão de riscos. A implementação nos dois projetos pilotos evidenciou, contudo, novos conflitos de papéis.

\section{Conflitos no disclosure de riscos estratégicos}

Após escolherem controladores internos e gestores aderentes à proposta de implementação, os auditores auxiliaram no mapeamento de riscos das autarquias. Dessa fase, resultaram matrizes nas quais riscos foram priorizados e ações de controle começaram a ser pensadas. O mapeamento visava alinhar os diferentes atores em torno de um contexto de conhecimento compartilhado (Jordan, et al., 2018; Jørgensen \& Jordan, 2016), o qual, no entanto, é marcado por diferentes perspectivas sobre o que deve ser considerado risco e como esse deve ser gerenciado (Arena, et al., 2017). O mapeamento destacou dificuldades no engajamento de gestores na implementação e divergências entre o que gestores e técnicos consideravam riscos.

A implementação na autarquia 1 contou com a participação do corpo dirigente e do controlador interno. No entanto, devido a mudanças no alto-escalão em virtude do período eleitoral, o trabalho foi suspenso. Segundo o controlador interno, apesar do trabalho de mapeamento ter sido feito, não havia certeza se o novo corpo dirigente iria dar continuidade ao trabalho ou se iria aceitar as prioridades levantadas pelo mapeamento. Adicionalmente, segundo esse controlador, não havia certeza se ele continuaria no cargo com a chegada do novo corpo dirigente. $\mathrm{Na}$ autarquia 2, a implementação avançou para além da fase de diagnóstico e mapeamento, mas contou com boicotes por parte de técnicos e diretores.

(controle interno) ...porque a [Auditoria Interna] chegou num momento aqui [na autarquia 2] fazendo uma fotografia, que o nosso projeto, para dar um aumento salarial que já não existe a 7 anos [...] o Estado cortou o aumento que dava anual, e além de tudo nós não entramos num projeto que tinha lá $[\ldots]$

(entrevistador) E qual é o impacto de vir falar com o pessoal sobre gestão de riscos? 
(controle interno) Muito complicado, aí mas assim oh, o que que acontece, o pessoal já fez outras análises SWOT aqui dentro que ficou na análise SWOT...mas não aconteceu nada...e dessa vez eu disse: "não pessoal, a gente vai fazer uma análise SWOT, a gente vai fazer ações, a gente vai ver o que tem de ação, o que não tem, vamos construir juntos"...

(Controle Interno, Entrevista 11).

Se por um lado, as resistências dos técnicos remetiam a iniciativas passadas frustradas, por outro, os boicotes dos diretores tinham motivações políticas. Embora o presidente da autarquia fosse apontado por um partido, diretores possuíam diferentes afiliações (mesmo quando do mesmo partido) e sentiam-se menos motivados a apoiar o projeto assumido pelo presidente.

(controle interno) Na verdade, existe problema político, também além do problema da comunicação, existia aquele "não quero ouvir o que esse cara está falando" [...]

(entrevistador) Mas mesmo sendo o diretor? E o presidente?

(controle interno) Sim, porque vou te contar uma coisa [...], ele [o diretor] era presidente, ele tinha vontade de estar no cargo dele [do presidente], então "quem me botou aqui não foi você, foi um outro partido, outra pessoa, não é nem outro partido, só que é outra pessoa então somos indicados diferentes [...] E aí o que acontece nas reuniões da gestão de risco, também foi boicote

(Controle Interno, Entrevista 11).

A estrutura de indicação política para os cargos da alta administração das autarquias fazia com que os auditores contassem mais com o corpo técnico do que com o suposto "dono do negócio". O presidente do órgão, por sua vez, apesar de aderente, contava mais com os técnicos do que com os diretores na implementação. Esse descompasso entre como gestores e técnicos engajaram-se ao processo de implementação, trouxe visões discrepantes sobre como os riscos deveriam ser divulgados.

$\mathrm{Na}$ autarquia 1 , o presidente entendia que problemas operacionais eram prioritários, em contraste com o que os técnicos do órgão entendiam. Na autarquia 2, após a fase de mapeamento, ao divulgarem os resultados para o dirigente, este ficou incomodado com a escolha de um risco nomeado "falhas de gestão". Os casos sublinham que dirigentes podem ser refratários à dar transparência a problemas de gestão, para se proteger de problemas de reputação e preservar capital político (Hood, 2002).

Apesar dos boicotes, a gestão de riscos ofereceu um vocabulário e ferramental para controles internos expandirem seu território, legitimando uma visão do controle interno para além da figura do secretário de controle interno.

(controle interno autarquia 2) O controle interno mudou totalmente [...] Assim oh, tu faz trabalho no RH, vai lá, conferência de ponto, o parecer das novas admissões, tu vai fazer um controle em cima dos processos licitatórios, o suprimento de fundo, de área, não sei o que, e hoje para mim [...], eu acho que o controle interno não tem que fazer esse trabalho, ele tem que fazer prevenção, orientar a casa para melhores procedimentos, para que a gente não tenha que ficar corrigindo, a gente está apagando fogo né, apagando incêndio, tu tá conferindo para saber se as pessoas estão fazendo certo, mas se elas estão sempre errando o que está errado antes disso né [...] (Controle Interno, Entrevista 11).

\section{DISCUSSÃO}

Os resultados acima confirmam que a introdução de inovações de controle requer o trabalho de atores com poder, um processo frequentemente permeado por adaptações e resistências (Lino, et al., 2019; Pinho, 2016; Souza, et al., 2020). Os resultados desse artigo contribuem para esse debate, ao apontar que a gestão de riscos pressiona agentes de controle - auditores e controladores internos - por uma revisão de papéis e formas de atuação. Essa seção discute, no entanto, o alcance limitado da adoção da gestão de riscos com um dos pilares do controle, quando desacoplada de uma reformulação dos incentivos para a transparência e divulgação de problemas estruturais na administração pública.

Embora auditores entusiastas tenham assumido a tarefa de disseminar práticas de gestão de riscos como parte do rol de atividades de controle interno no estado, esse processo não fez parte de uma discussão sobre as necessidades de reformulação de papéis e formas de prestação de contas e responsabilização de agentes públicos (Entrevista 13). 
Na ausência de mecanismos de responsabilização, que obrigassem os órgãos a adotar a gestão de riscos, auditores entusiastas tiveram que se aproximar de controladores internos e gestores para convencê-los dos benefícios da inovação. Isso ocorreu porque percebiam que os controladores internos nos órgãos estavam sobrecarregados e com demandas conflitantes produzidas por diferentes órgãos de controle, o que tornaria a implementação um processo difícil. A percepção de que a difusão da inovação requeria maior protagonismo da auditoria conflitava, contudo, com a lógica de conformidade e de atuação à distância que auditores estavam acostumados.

Sem alterar as rotinas dos controles internos, a implementação nos órgãos ocorreu com o auxílio de auditores, os quais entendiam ser necessário criar uma cultura de gestão de riscos para que a iniciativa fosse bem sucedida. No entanto, a descontinuidade em um projeto e os boicotes de diretores em outro apontam duas limitações na capacidade dos órgãos de prestarem contas e se responsabilizarem com base no risco.

Primeiro, no papel de gestores de riscos, agentes de controle buscam influenciar o processo de decisão, coletando e produzindo informação relevante para níveis estratégicos (Hall, et al., 2015; Rana, et al., 2019). No setor público, no entanto, esse alinhamento é um desafio, uma vez que a introdução da gestão de riscos chocase com a lógica de atuação desses atores, os quais, na ausência de respaldo normativo, têm dificuldade para avançar além da perspectiva de controle de natureza financeira-contábil. Uma vez que formas de controle negativo (controle sobre as pessoas) tem prevalência sobre controles da gestão, a gestão de riscos é incorporada como atividade acessória, portanto secundária, nas rotinas de prestação de contas. Normativas federais têm, de fato, sublinhado a responsabilidade da alta administração pela implementação e pelo acompanhamento de práticas de gestão de riscos. No entanto, desvinculadas de uma definição sobre como gestores serão avaliados por falhas em evidenciar e mitigar riscos, a adoção dessas práticas corre o risco de ocorrer de forma meramente cerimonial.

Segundo, gestores públicos costumam evitar o disclosure de informações que podem prejudicar seu capital político ou reputação (Hood, 2007). A vinculação político-partidária de presidentes no caso acima, demonstra não apenas como gestores indicados politicamente evitam dar visibilidade a problemas que ameacem seu capital político, mas também evidencia os desafios de alinhamento entre diretores que competem por esse capital político, e secretários de controle interno que dependem de informações de nível estratégico. Mais do que um problema pontual, esse desalinhamento limita substancialmente a capacidade dos controladores internos produzirem informação relevante e influenciarem níveis estratégicos a pensarem em termos de riscos.

No setor público, a gestão de riscos estratégicos depende, não raras vezes, de informações que encontramse espalhadas por diferentes órgãos, o que faz com que o envolvimento da alta administração seja fundamental para evidenciação de interdependências que ameaçam a política pública executada. A recente pandemia provocada pelo SARS-Cov-2 é um exemplo de como a existência dessas interdependências exige uma abordagem holística da gestão de riscos, uma vez que órgãos trabalhando em silo podem transferir riscos uns para os outros. No entanto, sem uma compreensão e reformulação dos incentivos embutidos nos processos de prestação de contas e responsabilização de agentes públicos, a incorporação da gestão de riscos no setor público corre o risco de ficar reduzida a uma ferramenta de melhoria de processos, com capacidade limitada para o enfrentamento de problemas estruturais.

\section{CONCLUSÃO E DIRECIONAMENTO PARA PESQUISAS FUTURAS}

Este artigo examinou os desafios da implementação da gestão de riscos em um governo estadual, em termos do impacto dessa inovação nas formas de prestação de contas e responsabilização de agentes públicos. Embora a literatura indique que a difusão de práticas de gestão de riscos no contexto anglo-saxão tenha implicado em uma colonização da administração pública em torno de uma nova lógica de accountabiltiy (Black, 2005; Power, 2004; Rothstein, Borraz, \& Huber, 2013), essa assimilação ocorreu de maneira seletiva no caso estudado (Oulasvirta \& Anttiroiko, 2017). Capitaneada por um grupo de auditores internos, a gestão de riscos serviu para legitimar os esforços de expansão do sistema de controle interno do estado. No entanto, a identidade profissional de auditores, a baixa relevância dos controles internos e divergências no disclosure de riscos estratégicos, apresentam limitações para que essa assimilação se traduza em ganhos para a administração de riscos sistêmicos no estado.

Compreender como práticas de gestão de riscos podem contribuir para a administração de problemas estruturais e complexos é um passo necessário para avançarmos em direção a uma lógica de accountability que faça sentido para a administração pública brasileira. Essa agenda é particularmente relevante, uma vez que inovações de controle devem ser adaptadas de forma reflexiva. Considerando-se o contexto de reformas tardias e accountability pouco desenvolvida da administração pública brasileira, essa assimilação deve ser encarada não apenas como uma questão de adaptação cultural, mas também, e principalmente, como um processo que produz consequências imprevistas e, algumas vezes, indesejadas. 
Esse artigo contribui para esse debate ao propor que desacoplada de uma revisão das formas de prestação de contas e responsabilização de agentes públicos, a gestão de riscos tem poder limitado na mitigação de riscos sistêmicos na administração pública.

Embora a pesquisa relatada limite-se à assimilação da gestão de riscos como prática de controle interno de um estado, pesquisas subsequentes podem avançar na compreensão dos desafios relacionados à introdução de diferentes práticas de gestão de risco no setor público brasileiro. Duas sugestões são deixadas aqui: 1) Em recente discussão, Steccolini (2019) tem alertado para a necessidade de melhor compreensão das relações entre a contabilidade pública e o amplo contexto da política e administração pública. Em termos de gestão de riscos, tal conselho é relevante, uma vez que precisamos de melhor compreensão sobre práticas que podem auxiliar no enfrentamento de problemas complexos (wicked problems) que perpassam diferentes políticas públicas e depende de esforços de coordenação entre múltiplos atores organizacionais. 2) Alinhado à primeira sugestão, estudos futuros podem colaborar com a compreensão de práticas interorganizacionais e interinstitucionais envolvidas na gestão de riscos sistêmicos. Essa é uma agenda discutida por Power (2016b), mas que ganha contornos diferentes no contexto brasileiro de fragmentação institucional e sobreposições entre múltiplos órgãos de controle.

\section{REFERÊNCIAS}

Aquino, A. C. B. d., Rocha, A. C., Olivieri, C., \& Pinho, J. A. G. d. (2018). Controle governamental, accountability e coprodução. Sociedade, Contabilidade e Gestão, 13(2), 123-127. DOI: https://doi.org/10.21446/scg_ufrj. v13i2.19763

Arena, M., Arnaboldi, M., \& Palermo, T. (2017). The dynamics of (dis)integrated risk management: A comparative field study. Accounting, Organizations and Society, 62(65-81). DOI: https://doi.org/10.1016/j.aos.2017.08.006

Beassuier, A.-L., Demeritt, D., Griffiths, A., \& Rothstein, H. (2016). Accounting for failure: risk-based regulation and the problems of ensuring healthcare quality in the NHS. Health, Risk \& Society, 18(3-4), 205-224.

Bieder, C., \& Bourrier, M. (2013). Trapping safety into rules: How desirable or avoidable is proceduralization? London: Taylor \& Francis Group. DOI: https://doi.org/10.1201/9781315549774

Black, J. (2005). The emergence of risk-based regulation and the new public risk management in the United Kingdom. Public Law, Autumn, 510-549.

Carlsson-Wall, M., Kraus, K., Meidell, A., \& Tran, P. (2017). Managing risk in the public sector: The interaction between vernacular and formal risk management systems. Financial Accountability and Management, 35(1), 3-19. DOI: https://doi.org/10.1111/faam.12179

Castro, D. P. d. (2015). Auditoria, Contabilidade e Controle Interno no Setor Público. São Paulo: Editora Atlas.

Godoi, C. K., \& Mattos, P. L. C. L. (2006). Entrevista qualitativa: instrumento de pesquisa e evento dialógico. In C. K. Godoi, R. Bandeira-de-Mello \& A. B. Silva (Eds.), Pesquisa qualitativa em Estudos Organizacionais. São Paulo: Saraiva.

Hall, M., \& Fernando, R. (2016). Beyond the headlines. In M. Power (Ed.), Riskwork: Essays on the organizational life of risk management (pp. 72-90). Oxford: Oxford University Press. DOI: https://doi.org/10.1093/ acprof:oso/9780198753223.003.0004

Hall, M., Mikes, A., \& Millo, Y. (2015). How do risk managers become influential? A field study of toolmaking in two financial institutions. Management Accounting Research, 26, 3-22.

Hood, C. (2002). The risk game and the blame game. Government and Opposition, 37(1), 15-37. DOI: https://doi. org/10.1111/1477-7053.00085

Hood, C. (2007). What happens when transparency meets blame-avoidance? Public Management Review, 9(2), 191-210. DOI: https://doi.org/10.1080/14719030701340275

Hood, C., \& Rothstein, H. (2000). Business risk management in governemnt: pitfalls and possibilities. CARR Discussion Paper No. 0. DOI: http://dx.doi.org/10.2139/ssrn.471221

IFAC. (2014). International framework: Good Governance in the Public Sector. London: Chartered Institute of Public Finance and Accountancy (CIPFA) and the International Federation of Accountants (IFAC).

IIARF. (2009). Internal Audit Capability Model for the Public Sector. Altamonte Springs, Florida: The Institute of Internal Auditors Research Foundation. 
Jordan, S., Mitterhofer, H., \& Jørgensen, L. (2018). The interdiscursive appeal of risk matrices: Collective symbols, flexibility normalism and the interplay of 'risk' and 'uncertainty'. Accounting, Organizations and Society, 67, 34-55. DOI: https://doi.org/10.1016/j.aos.2016.04.003

Jørgensen, L., \& Jordan, S. (2016). Risk mapping. In M. Power (Ed.), Riskwork: Essays on the organizational life of risk management (pp. 50-71). Oxford: Oxford University Press. DOI: https://doi.org/10.1093/ acprof:oso/9780198753223.003.0003

Lino, A. F., Carvalho, L. B. d., Aquino, A. C. B. d., \& Azevedo, R. R. d. (2019). A falta de trabalho institucional e mudanças incompletas em municípios brasileiros. Revista de Administração Pública, 53(2), 375-391. DOI: http://dx.doi.org/10.1590/0034-761220170404

Loureiro, M. R., Abrucio, F. L., \& Teixeira, M. A. C. (2012). Do controle interno ao controle social: a múltipla atuação da CGU na democracia brasileira. Cadernos Gestão Pública e Cidadania, 17(60). DOI: http://dx.doi. org/10.12660/cgpc.v17n60.3980

Lukka, K., \& Modell, S. (2010). Validation in interpretive management accounting research. Accounting, Organizations and Society, 35(4), 462-477. DOI: https://doi.org/10.1016/j.aos.2009.10.004

Machado, M. R., \& Paschoal, B. (2016). Monitorar, investigar, responsabilizar e sancionar: a multiplicidade institucional em casos de corrupção. Novos Estudos: Cebrap (104), 11-36. DOI: http://dx.doi.org/10.25091/ s0101-3300201600010001

Maguire, S., \& Hardy, C. (2016). Riskwork. In M. Power (Ed.), Riskwork: Essays on the organizational life of risk management (pp. 130-149). Oxford: Oxford University Press. DOI: https://doi.org/10.1093/ acprof:oso/9780198753223.003.0007

Mantere, S., \& Ketokivi, M. A. (2013). Reasoning in organization science. Academy of Management Review, 38(1), 70-89. DOI: https://doi.org/10.5465/amr.2011.0188

Mikes, A. (2011). From counting risk to making risk count: Boundary-word in risk management. Accounting, Organizations and Society, 36(4-5), 226-245. DOI: https://doi.org/10.1016/j.aos.2011.03.002

NAO. (2000). Supporting Innovation: Managing risk in government departments. London.

OCDE. (2010). Risk and Regulatory Policy: Improving the Governance of Risk. Paris: OCDE Publisher. DOI: https://doi.org/10.1787/9789264082939-en

Oulasvirta, L., \& Anttiroiko, A. V. (2017). Adoption of comprehensive risk management in local government. Local Government Studies, 43(3), 1-26. DOI: https://doi.org/10.1080/03003930.2017.1294071

Pinho, J. A. G. d. (2016). Reforma da administração pública no Brasil: A resistência do "bunker" patrimonialista e a reforma que não acontece. Sociedade, Contabilidade e Gestão, 11(3), 130-140. DOI: https://doi.org/10.21446/ scg_ufrj.v11i3.13392

Power, M. (2004). The Risk Management of Everything. London: Demos. DOI: https://doi.org/10.1108/eb023001

Power, M. (2009). The risk management of nothing. Accounting, Organizations and Society, 34, 849-855. DOI: https://doi.org/10.1016/j.aos.2009.06.001

Power, M. (2016a). Introduction: The organizational life of risk management. In M. Power (Ed.), Riskwork: Essays on the organizational life of risk management (pp. 1-25). Oxford, UK: Oxford University Press. DOI: https:// doi.org/10.1093/acprof:oso/9780198753223.003.0001

Power, M. (2016b). Postscript: On riskwork and auditwork. In M. Power (Ed.), Riskwork: Essays on the organizational life of risk management (pp. 274-284). Oxford: Oxford University Press. DOI: https://doi. org/10.1093/acprof:oso/9780198753223.003.0014

Rana, T., Wickramasinghe, D., \& Bracci, E. (2019). New development: integrating risk management in management control systems-lessons for public sector managers. Public Money \& Management, 39(2), 148-151. DOI: https://doi.org/10.1080/09540962.2019.1580921

Raupp, F. M., \& Pinho, J. A. G. d. (2015). Prestação de contas no legislativo local antes e depois da lei de acesso à informação. Contexto, 15(29), 30-46. DOI: http://repositorio.ufba.br/ri/handle/ri/21968

Rothstein, H., Borraz, O., \& Huber, M. (2013). Risk and the limits of governance: Exploring varied patterns of riskbased governance accross Europe. Regulation \& Governance, 7(2), 215-235. DOI: https://doi.org/10.1111/ j.1748-5991.2012.01153.x 
Rothstein, H., Huber, M., \& Gaskell, G. (2006). A theory of risk colonization: The spiraling regulatory logics of societal and institutional risk. Economy and Society, 35(1), 91-112. DOI: https://doi.org/10.1080/03085140500465865

Sacramento, A. R. S., \& Pinho, J. A. G. d. (2016). The process of implementing aswerability in contemporary Brazil. Revista de Administração Pública, 50(2), 193-213. DOI: http://dx.doi.org/10.1590/0034-7612147614

Souza, F. S. R. N. d., Braga, M. V. d. A., Cunha, A. S. M. d., \& Sales, P. D. B. d. (2020). Incorporação de modelos internacionais de gerenciamento de riscos na normativa federal. Revista de Administração Pública, 54(1), 59-78. DOI: http://dx.doi.org/10.1590/0034-761220180117x

Steccolini, I. (2019). Accounting and the post-new public management: re-considering publiciness in accounting research. Accounting, Auditing \& Accountability Journal, 32(1), 255-279. DOI: https://doi.org/10.1108/ AAAJ-03-2018-3423

Ungaro, G. G., \& Soré, R. R. (2014). Panorama do Controle Interno no Brasil. Brasília: CONACI.

Vaughan, D. (1996). The Challenger Launch Decision. Chicago: Chicago University Press. DOI: https://doi. org/10.7208/chicago/9780226346960.001.0001

Vieira, J. B., \& Barreto, R. T. d. S. (2019). Governança, Gestão de Riscos e Integridade. Brasília: Enap. Disponível: http://repositorio.enap.gov.br/handle/1/4281

Weaver, R. K. (1986). The politics of blame avoidance. Journal of Public Policy, 6(4), 371-398. DOI: https://doi. org/10.1017/s0143814x00004219

\section{Como citar este artigo}

Klein Junior, V. H. (2020). Gestão de riscos no Setor Público brasileiro: uma nova lógica de accountability?. Revista de Contabilidade e Organizações, 14:e163964. DOI: http://dx.doi.org/10.11606/issn.1982-6486. rco.2020.163964 